\title{
Therapeutic Drug Monitoring: Performance of a FRET-Based Point-Of-Care Immunoassay for the Quantitation of Infliximab and Adalimumab in Blood
}

AUTHORS:

Edgar Ong, Ruo Huang, Richard Kirkland, Stefan Westin, Jared Salbato, Kurtis Bray, Valerie Day, Larry Mimms, Michael Hale

AFFILIATIONS:

ProciseDx Inc., San Diego, CA

CORRESPONDING AUTHOR:

Edgar Ong, Ph.D.

ProciseDx Inc.

9449 Carroll Park Drive

San Diego, CA 92121

edgar.ong@procisediagnostics.com

KEYWORDS:

Adalimumab

Biosimilars

Crohn's disease

Fluorophore

FRET

Inflammatory bowel disease

Infliximab

Lumiphore

Point-of-care

Therapeutic drug monitoring

Tumor necrosis factor

Ulcerative colitis

\section{ABSTRACT}

Two fast ( $<5 \mathrm{~min}$ ), time-resolved fluorescence resonance energy transfer (FRET)-based immunoassays (Procise IFX ${ }^{\mathrm{TM}}$ and Procise ADL ${ }^{\mathrm{TM}}$ ) were developed for the quantitative detection of infliximab (IFX), adalimumab (ADL), and their respective biosimilars for use in therapeutic drug monitoring (TDM) using $20 \mu \mathrm{L}$ of finger prick whole blood at the point-of-care or whole blood/serum in a central lab. Studies were performed to characterize analytical performance of the Procise IFX and the Procise ADL assays on the ProciseDx ${ }^{\mathrm{TM}}$ analyzer. 
The Procise IFX and Procise ADL assays both showed good analytical performance with respect to sensitivity, specificity, linearity, and precision suitable for routine clinical use as well as excellent correlation to current commercial ELISA IFX and ADL measurement methods.

Results indicated that the Procise IFX and Procise ADL assays are sensitive, specific, and precise yielding results in less than 5 minutes from either whole blood or serum. This indicates the Procise IFX and Procise ADL assays are useful for obtaining fast and accurate IFX or ADL quantitation, thus avoiding delays inherent to current methods and enabling immediate drug level dosing decisions to be made during a single patient visit.

\section{INTRODUCTION}

Infliximab (IFX; trade name: Remicade ${ }^{\circledR}$ ) is a chimeric human-murine monoclonal antibody specific for human tumor necrosis factor (TNF) that is approved for reducing signs and symptoms and for induction and maintenance of remission in patients with moderate to severe luminal or fistulizing Crohn's disease (CD), moderate to severe ulcerative colitis (UC), and pediatric CD or UC refractory to conventional therapy. ${ }^{1}$ Other approved indications for IFX include rheumatoid arthritis, ankylosing spondylitis, psoriatic arthritis, and plaque psoriasis. ${ }^{1}$

Adalimumab (ADL; trade name: Humira ${ }^{\circledR}$ ) is a recombinant fully-human IgG1 monoclonal antibody specific for human TNF. ADL was created using phage display technology resulting in an antibody with human derived heavy and light chain variable regions and human IgG1:k constant regions. ADL is approved for reducing signs and symptoms and induction and maintenance of remission in patients with moderate to severe $C D$, moderate to severe $U C$, and pediatric $C D$ or $U C$ refractory to conventional therapy. Other approved indications for ADL include rheumatoid arthritis, juvenile rheumatoid arthritis, ankylosing spondylitis, psoriatic arthritis, plaque psoriasis, hidradenitis suppurativa, and intermediate, posterior, and panuveitis. ${ }^{2}$

Measurement of IFX or ADL concentrations in human blood has shown utility in optimizing IFX or ADL dosing and in managing inflammatory bowel disease (IBD) activity and has demonstrated ability to aid in the management of both UC and CD. Therapeutic drug monitoring (TDM) of IFX and ADL levels in the management of IBD patients has become accepted as the standard of care for the management of IBD. ${ }^{3}$ Therapeutic monitoring of IFX and ADL has come to be recognized and recommended by expert panels, ${ }^{4}$ in international consensus statements, $, 5,6$ and in gastroenterological practice guidelines in the United States. ${ }^{7,8}$

The Procise IFX and Procise ADL assays are both homogeneous assays that use a fluorescence resonance energy transfer (FRET) signal to detect the presence and quantity the target analyte. FRET is a process in which a donor molecule (Lumiphore ${ }^{\circledR}$ ), in an excited state, transfers excitation energy through dipole-dipole coupling to an acceptor fluorophore when the two are brought into close proximity. Upon excitation at a characteristic wavelength the energy absorbed by the donor is transferred to the acceptor, which in turn emits light energy. The level of light emitted from the acceptor fluorophore is directly proportional to the degree of donor/acceptor complex formation.

The Procise IFX and Procise ADL assays each require two separate binding events to ensure specificity. The first binding event is the IFX or ADL drug to a TNF-labeled donor. The second binding 
event uses a monoclonal Fab anti-IFX/TNF or anti-ADL/TNF complex labeled with an acceptor fluorophore. As the concentration of active IFX or ADL increases, a proportional increase in signal is observed. A schematic of the operation of FRET assay is shown in Figure 1

Point-of-care testing of IFX and ADL can provide convenience as well as enhanced speed of result turn-around for improved patient management. Thus, the purpose of this study was to validate the performance of the Procise IFX and Procise ADL assays to determine their suitability for use as pointof-care assays for IFX and ADL TDM.

\section{MATERIALS AND METHODS}

\section{Analyzer}

The ProciseDx analyzer (Figure 2) is a small desktop analyzer weighing about $4.5 \mathrm{~kg}$. It uses a UV LED to excite a proprietary terbium cryptate fluorophore, used as a donor that is covalently bound to a key reagent used to detect the analyte of interest (IFX or ADL) within the assay. The donor, when in proximity to an acceptor bound to a different antigen or antibody used to detect the analyte of interest, excites the acceptor causing light to emit at a specific wavelength. The analyzer measures the signal at specific wavelengths of interest to analyze the reaction (donor and acceptor) by filtering the light through specific band pass filters and reading the signal at each wavelength of interest with a silicon photomultiplier (SiPM). The intensity of the fluorescent signal emitted from the Reaction Cartridge is converted to Relative Fluorescence Units (RFUs) and the RFU then undergoes final analysis and determination of a test result based on an algorithm described within assay specific method file and reported as IFX or ADL concentration in units of $\mu \mathrm{g} / \mathrm{mL}$.

The Analyzer has been designed with fail-safe features including use of sensors, 1-D and 2-D barcodes, controlled access via Operator or Supervisor user levels, periodic calibration check, GUI interface messaging and Power on Self-Test (POST). The checks are conducted automatically at POST and during operation to ensure the Analyzer is operating to its specifications. If any of these safety features fail, the Analyzer will alert the user and prevent tests from running. The analyzer ensures all safety features are tested at least once a week and most are run during each test.

\section{Reagents and Assay Operation}

The primary reagents for both the Procise IFX and Procise ADL assays consist of a single-use Reaction Cartridge and a premeasured buffer solution in a plastic bulb. The cartridge cap is designed to hold lyophilized beads containing assay specific donor and acceptor fluorophore labeled reagents (Figure 3.). The Procise IFX and Procise ADL assay formats are both designed using a sandwich assay format. Both assays utilize a TNF $\alpha$ donor fluorophore labeled protein and a rabbit monoclonal antigen-binding fragment (Fab) labeled with an acceptor fluorophore. Both Fab monoclonals were designed to bind to the TNF drug complex and are specific to either IFX or ADL. No IFX cross reactivity was observed in the ADL assay and no ADL cross reactivity was observed in the IFX assay. The donor has three usable spectrally distinct emission peaks: 490, 550 and $620 \mathrm{~nm}$. For the Procise IFX and Procise ADL assays the energy transfer occurs using the $490 \mathrm{~nm}$ peak to the AlexaFluor 488 acceptor. The assay format and spectra are summarized in Figure 1. Like other sandwich assay formats, as the concentration of IFX or ADL increases a directly proportional increase in the signal is observed. 
The assay reaction is started by pipetting $20 \mu \mathrm{L}$ of the whole blood or serum specimen, dispensing the premeasured contents of one buffer bulb into the reaction cartridge, and mixing by inversion. The cartridge is then inserted into the analyzer for automatic incubation and reading, which takes less than 5 minutes. The instrument automatically measures and corrects for differences created by presence or absence of blood cells (whole blood vs. serum), variability in hematocrit between whole blood specimens, and reports the assay results.

Establishment of Assay Calibration

The accuracy of the Procise IFX assay was established through calibrators and controls traceable to the WHO 1st International Standard for Infliximab (NIBSC code: 16/170). The accuracy of the Procise ADL assay was established through calibrators and controls traceable to the WHO $1^{\text {st }}$ International Standard for Adalimumab (NIBSC code: 17/236).

Determination of Analytical Sensitivity and Linearity Analytical testing was performed by spiking known amounts of IFX or ADL into negative serum and whole blood specimens. Analytical sensitivity was determined using limiting concentrations of the drug. Linearity was determined by testing IFX across the assay range. Both testing followed CLSI Guideline, EP6-A Evaluation of the Linearity of Quantitative Measurement Procedures: A Statistical Approach; Approved Guideline and EP17-A2 Evaluation of Detection Capability for Clinical Laboratory Measurement Procedures; Approved Guideline - 2 ${ }^{\text {nd }}$ Edition.

Determination of Precision

Procise IFX precision testing was performed using 2 reagent lots, 1 operator, 2 runs per day, 2 reps per run across 20 days of testing. Procise ADL precision testing was performed using 2 reagent lots, 1 operator, 2 runs per day, 2 reps per run across 10 days of testing. Coefficients of variation (\%CV) were calculated consistent with CLSI Guideline, EP05-A3 Evaluation of Precision Performance of Quantitative Measurement Methods.

Method Comparison

The analytical agreement and correlation between the Procise IFX and Procise ADL assays were also compared head-to-head with another CE-marked commercial assay: LISA-TRACKER Infliximab ELISA test and LISA-TRACKER Adalimumab ELISA test (Theradiag, France). Assays were run according to manufacturer's instructions. Note that the LISA-TRACKER Infliximab ELISA test calibration is traceable to the WHO 1st International Standard for Infliximab. The LISA-TRACKER Adalimumab ELISA test was commercially released prior to the availability of the WHO 1st International Standard for Adalimumab in January 2020.

Serum specimens were deidentified leftover clinical laboratory specimens from IBD patients undergoing either IFX or ADL therapy. Whole blood specimens were derived from normal whole blood specimens that were spiked with either IFX or ADL to achieve varying concentrations across the assay range. Statistical analysis of the agreement was determined by Deming linear regression.

Analytical Specificity

The extent to which various potentially cross reacting and interfering substances influence the results of the Procise IFX and Procise ADL assays was determined by testing specimens spiked with 
increasing concentrations of the potential interferents to observe for significant interference in the IFX or ADL quantitation. Significant interference was defined as $\pm 10 \%$ of the expected value.

\section{RESULTS}

Procise IFX Assay

The Procise IFX assay showed a Limit of Blank (LOB), Limit of Detection (LOD), and Lower Limit of Quantitation (LLOQ) of $0.1,0.2$, and $1.1 \mu \mathrm{g} / \mathrm{mL}$ in serum and $0.6,1.1$, and $1.7 \mu \mathrm{g} / \mathrm{mL}$ in whole blood, respectively. The linear assay range was determined to be 1.7 to $77.2 \mu \mathrm{g} / \mathrm{mL}$ in serum and whole blood.

Assay precision testing across 20 days with multiple runs and reagent lots showed an intra-assay coefficient of variation (CV) of $2.7 \%$, an inter-assay CV of $<2 \%$, and a total CV of $3.4 \%$ (Table 1 ). A good correlation to the Theradiag Infliximab ELISA was obtained for both serum (slope=1.01; $r=0.99$ ) and whole blood (slope=1.01; $r=0.98$ ) samples (Figure 4). Testing of biosimilars (infliximabdyyb - trade name: Inflectra ${ }^{\circledR}$ and infliximab-abda - trade name Renflexis ${ }^{\circledR}$ ) showed good recovery (data not shown).

The analytical specificity of the Procise IFX assay as measured by interference in assay quantitation of various potentially cross-reacting or interfering substances fell within acceptable limits and is shown in Table 3.

Procise ADL Assay

The Procise ADL assay showed a LOB, LOD, and LLoQ of 0.1, 0.2, and $0.6 \mu \mathrm{g} / \mathrm{mL}$ in serum and 0.5, 0.9 , and $1.3 \mu \mathrm{g} / \mathrm{mL}$ in whole blood, respectively. The linear assay range was determined to be 1.3 to $51.5 \mu \mathrm{g} / \mathrm{mL}$ in serum and whole blood.

Assay precision testing across 10 days with multiple runs and reagent lots showed an intra-assay CV of $2.8 \%$, an inter-assay CV of $\leq 1.5 \%$, and a total CV of 3.5\%. (Table 2).

A good correlation to the Theradiag Adalimumab ELISA was obtained for both serum (slope $=0.94$; $r=0.99$ ) and whole blood (slope=1.13; $r=0.98$ ) samples (Figure 5). Testing of biosimilars (adalimumab-atto - trade name: Amjevita ${ }^{\circledR}$ and adalimumab-xxxx - trade name: Imraldi ${ }^{\circledR}$ ) showed good recovery (data not shown).

The analytical specificity of the Procise ADL assay as measured by interference in assay quantitation of various potentially cross-reacting or interfering substances fell within acceptable limits and is shown in Table 3.

\section{DISCUSSION}

Multiple studies have assessed the relationship between IFX and ADL levels and the outcomes in patients with IBD. 9-12 Among other potential mechanisms, subtherapeutic concentrations of IFX or $A D L$ and/or development of anti-drug antibodies may be responsible for loss of therapeutic 
response. ${ }^{13-15}$ Thus, maintaining proper therapeutic levels of anti-TNF drug in the blood has become an important target in the management of IBD.

As TDM of IFX and ADL has become increasingly common in the management of IBD, it has come to be routinely used in the mode of reactive testing - which is testing done in response to the appearance or worsening of IBD symptoms to determine whether there is sufficient drug present in circulation to maintain remission. ${ }^{16-18}$ Increasingly, anti-TNF biologics are also being monitored in the more optimal approach of proactive testing - which is testing of the patient undergoing biologic therapy while the disease is still in remission to allow optimization of dosing in advance and avoiding loss of response and helping to prevent cumulative damage to the bowel. ${ }^{18}$

The quantitative Procise IFX and Procise ADL assays and ProciseDx analyzer are designed for pointof-care use. The primary workflow has been designed to be simple by following the workflow of CLIAwaived assays. This offers advantages in immediate access, ease of specimen collection, and quick turn-around of TDM results compared to traditional central laboratory ELISA or send-out laboratory developed tests.

The findings of this study have confirmed that both the Procise IFX and Procise ADL assays provide good analytical performance and excellent correlation to an existing commercial assay sufficient to support their use in point-of-care laboratories and physicians' offices. This convenience of location, ease of use, and quick availability of assay results may increase the use and enhance the usefulness of both reactive and proactive TDM for these IBD biologic agents.

This study is primarily analytical and does not offer direct comparisons between the Procise assay results and the clinical state of patients. However, excellent analytical correlation to assays already commercialized and in routine clinical use suggest that Procise IFX and Procise ADL assays will also prove to be clinically useful but with the added advantages of point-of-care availability and use of finger prick specimens. Ongoing future retrospective and prospective clinical studies will focus on directly demonstrating clinical utility in IBD patients receiving IFX or ADL therapy.

\section{ACKNOWLEDGEMENT}

The authors wish to acknowledge Kevin Chon, Rukmini Reddy, Raj Srikrishnan, Matthew Wong, and Amparo Ng for their technical contributions.

\section{DISCLOSURE}

All authors are employees of ProciseDx Inc.

\section{REFERENCES}

1. Remicade ${ }^{\circledR}$ (infliximab) package insert. Horsham, PA: Janssen Biotech, Inc.

2. Humira ${ }^{\circledR}$ (adalimumab) package insert. North Chicago, IL: AbbVie Inc. 
3. Vaughn B, Sandborn WJ, Cheifetz AS. Biologic concentration testing in inflammatory bowel disease. Inflamm Bowel Dis. 2015 Jun;21(6):1435-42.

4. Melmed GY, Irving PM, Jones J, et al. Appropriateness of testing for anti-tumor necrosis factor agent and antibody concentrations, and interpretation of results. Clin Gastroenterol Hepatol. 2016 Sep;14(9):1302-9.

5. Mitrev N, Vande Casteele N, Seow CH, et al. Review article: consensus statements on therapeutic drug monitoring of anti-tumour necrosis factor therapy in inflammatory bowel diseases. Aliment Pharmacol Ther. 2017 Dec;46(11-12):1037-1053.

6. Papamichael K, Cheifetz AS, Melmed GY, et al. Appropriate therapeutic drug monitoring of biological agents for patients with inflammatory bowel diseases. Clin Gastroenterol Hepatol. 2019; $17: 1655-1668$.

7. Vande Casteele $\mathrm{N}$, Herfarth $\mathrm{H}$, Katz J, et al. American gastroenterological association institute technical review on the role of therapeutic drug monitoring in the management of inflammatory bowel diseases. Gastroenterol. 2017 Sep;153(3):835-857.

8. Feuerstein JD, Nguyen GC, Kupfer SS, et al. American gastroenterological association institute guideline on therapeutic drug monitoring in inflammatory bowel disease. Gastroenterol. 2017 Sep;153(3):827-834.

9. Ungar B, Levy I, Yavne Y, et al. Optimizing Anti-TNF- $\alpha$ Therapy: Serum Levels of Infliximab and Adalimumab Are Associated With Mucosal Healing in Patients With Inflammatory Bowel Diseases. Clin Gastroenterol Hepatol. 2016 Apr;14(4):550-557.

10. Hanauer SB, Sandborn WJ, Rutgeerts $P$, et al. Human Anti-Tumor Necrosis Factor Monoclonal Antibody (Adalimumab) in Crohn's Disease: The CLASSIC-I Trial. Gastroenterology. 2006 Feb;130(2):323-33.

11. Sandborn WJ, Hanauer SB, Rutgeerts $P$, et al. Adalimumab for Maintenance Treatment of Crohn's Disease: Results of the CLASSIC II Trial. Gut. 2007 Sep;56(9):1232-9.

12. Colombel JF, Sandborn WJ, Rutgeerts P, et al. Adalimumab for Maintenance of Clinical Response and Remission in Patients With Crohn's Disease: The CHARM Trial. Gastroenterology. 2007 Jan;132(1):52-65.

13. Lin K, and Mahadevan U. Pharmacokinetics of biologics and the role of therapeutic monitoring. Gastroenterol Clin North Am. 2014 Sep; 43(3): 565-79.

14. Wolf D, D'Haens G, Sandborn WJ, et al. Escalation to weekly dosing recaptures response in adalimumab-treated patients with moderately to severely active ulcerative colitis. Aliment Pharmacol Ther. 2014 Sep; 40(5): 486-97.

15. Strik AS, Bots SJ, D'Haens G, et al. Optimization of anti-TNF therapy in patients with Inflammatory Bowel Disease. Expert Rev Clin Pharmacol. 2016; 9(3): 429-39.

16. Vaughn BP, Martinez-Vazquez M, Patwardhan VR, et al. Proactive therapeutic concentration monitoring of infliximab may improve outcomes for patients with inflammatory bowel disease: results from a pilot observational study. Inflamm Bowel Dis. 2014 Nov;20(11):1996-2003. 
17. Lau C, Dubinsky M, Melmed G, et al. The impact of preoperative serum anti-tnf $\alpha$ therapy levels on early postoperative outcomes in inflammatory bowel disease surgery. Ann Surg. 2015 Mar; 261(3): 487-496.

18. Papamichael K, Chachu KA, Vajravelu RK, et al. Improved long-term outcomes of patients with inflammatory bowel disease receiving proactive compared with reactive monitoring of serum concentrations of infliximab. Clin Gastroenterol Hepatol. 2017 Oct;15(10):1580-1588. 


\section{FIGURES}

Figure 1. A representation of the Procise IFX and Procise ADL sandwich assay format.

As depicted in Fig. 1 a FRET emission signal from the acceptor is only created in the presence of drug within the sample. Both IFX and ADL use different monoclonal drug complex Fabs that are specific to their respective drug.

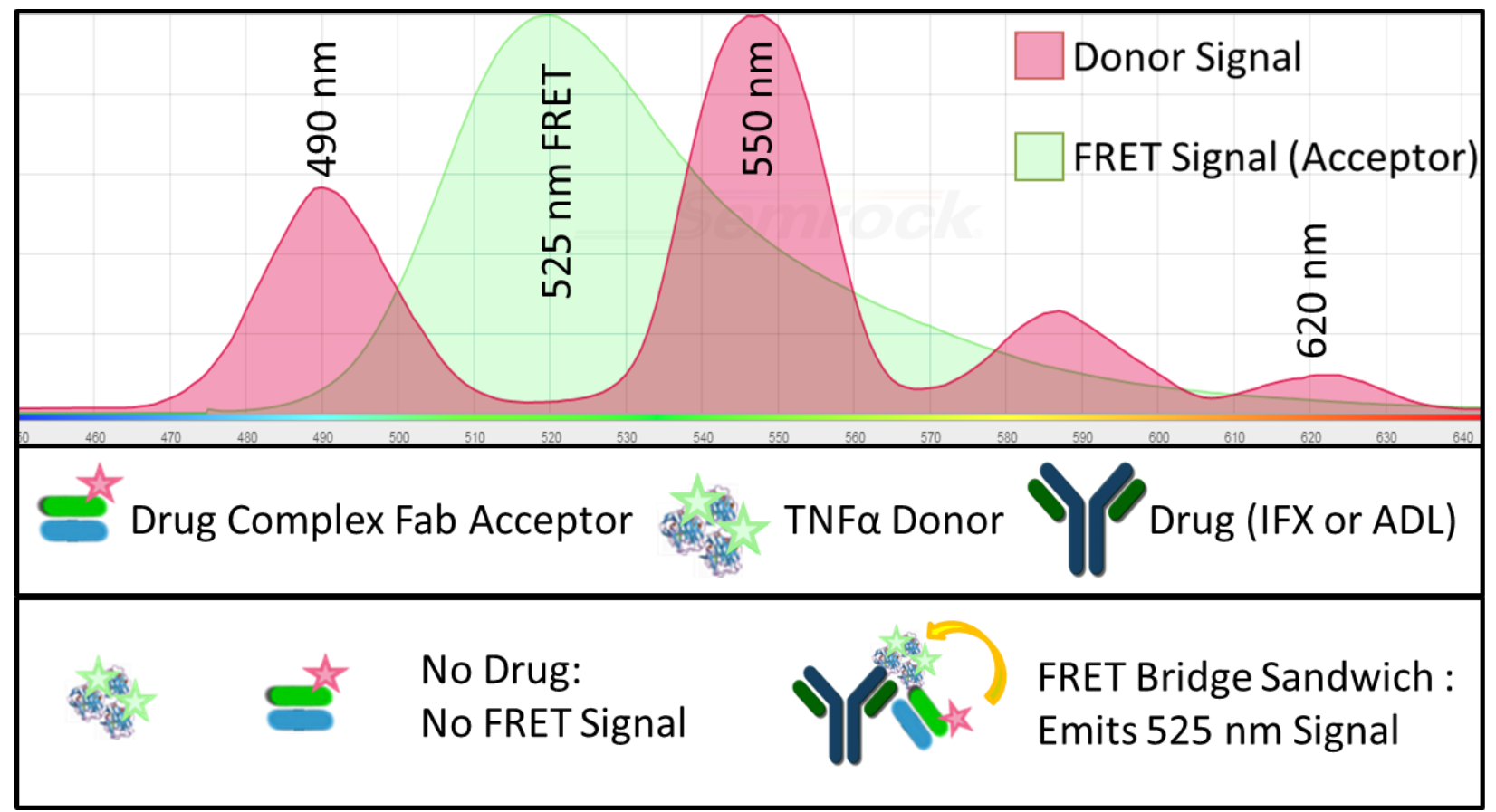

Figure 2 The ProciseDx Analyzer with Single-Use Reaction Cartridge.

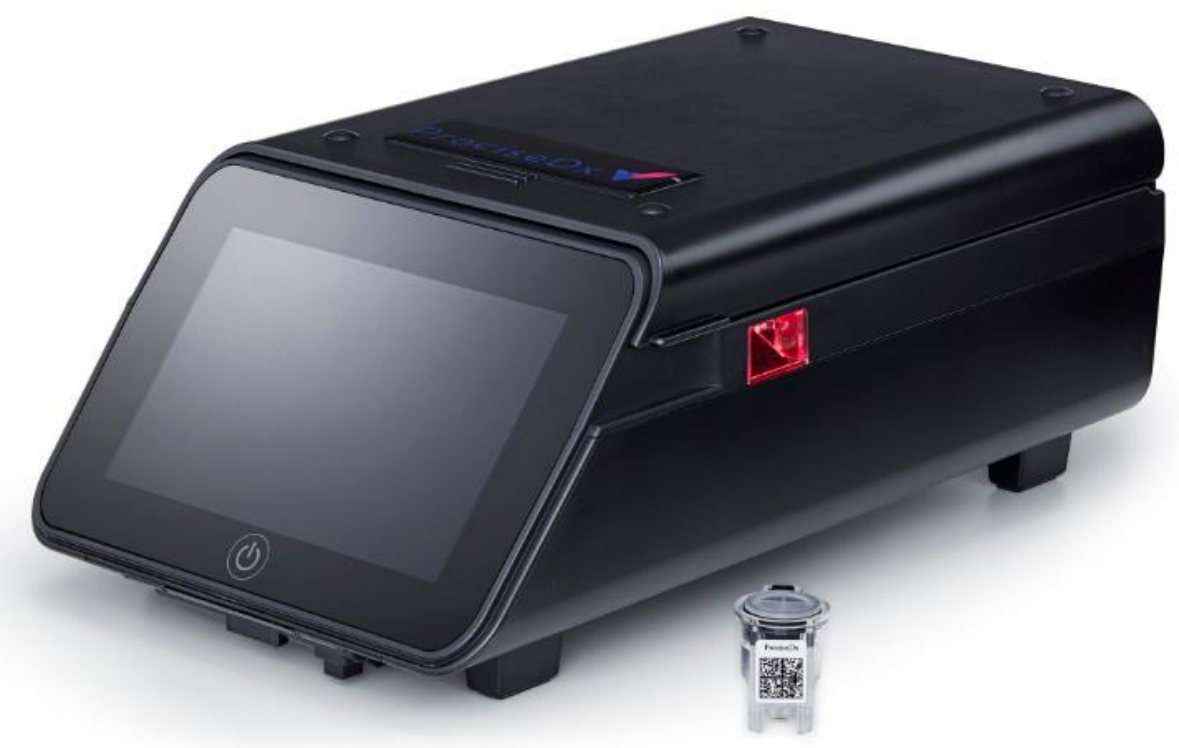


Figure 3. The Reagent Cartridge - Exterior (Left) and Cut-Away View Showing Reagent Bead (right)

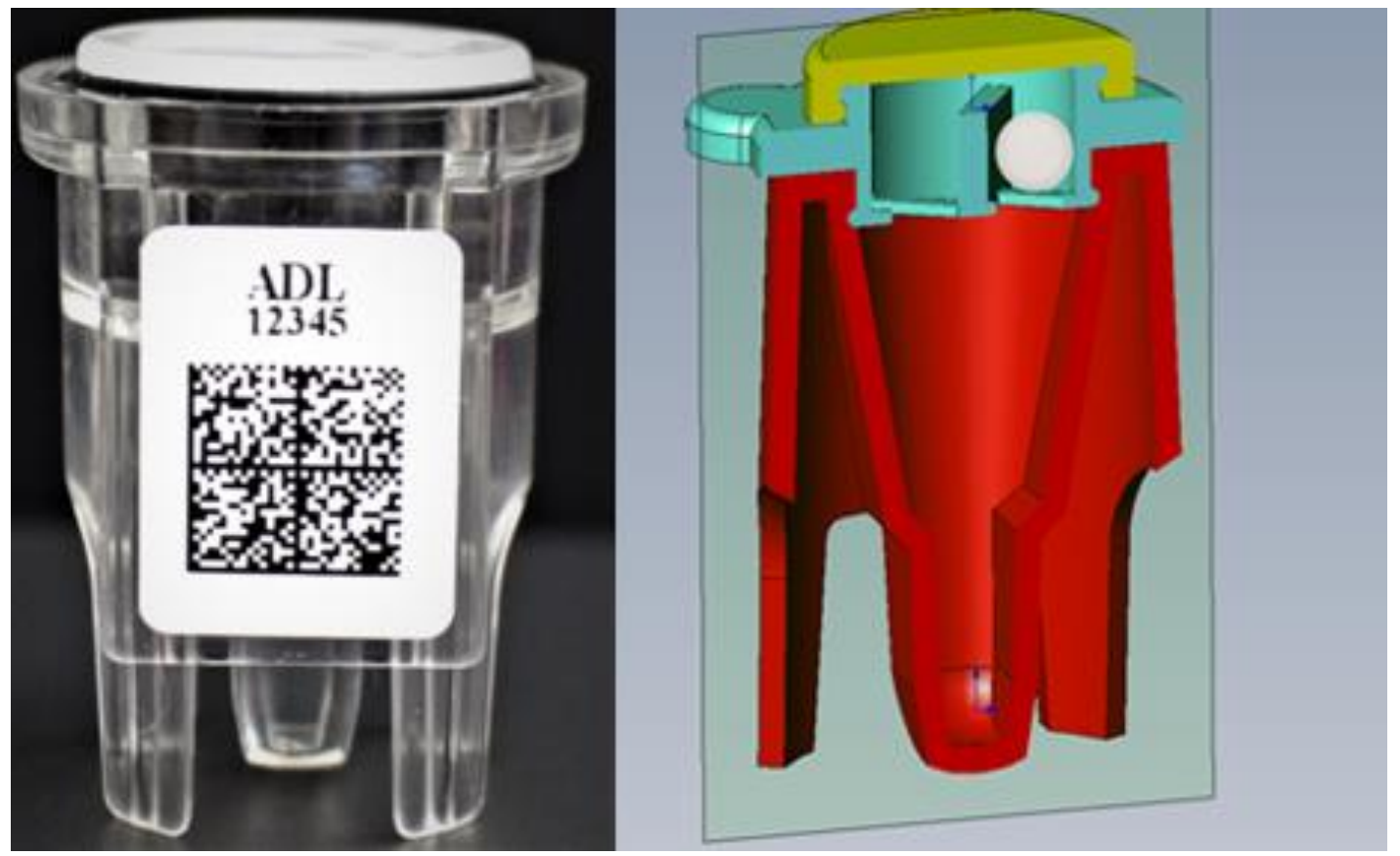

Figure 4. Assay correlation between Procise IFX and Theradiag tests in serum specimens (left) and in whole blood (Procise) vs. plasma (Theradiag) specimens (right).
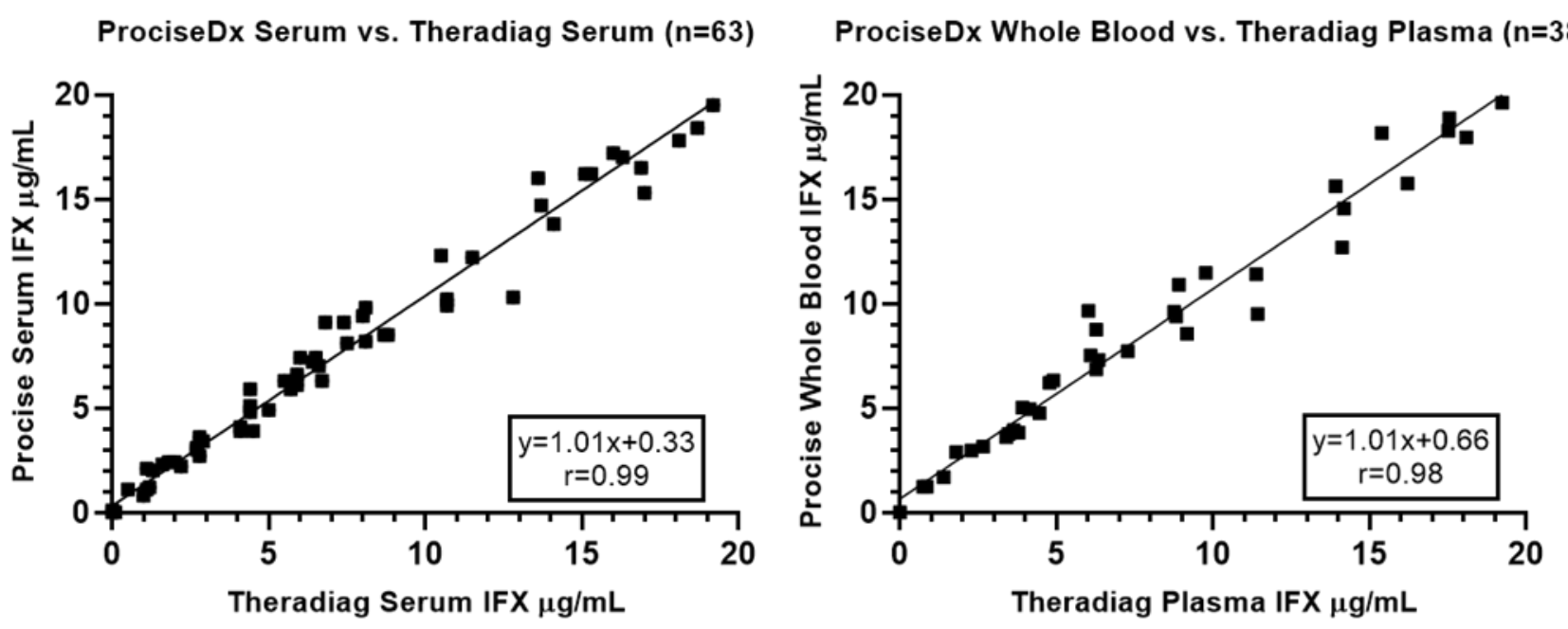
Figure 5. Assay correlation between Procise ADL and Theradiag tests in serum specimens (left) and in whole blood (Procise) vs. plasma (Theradiag) specimens (right).
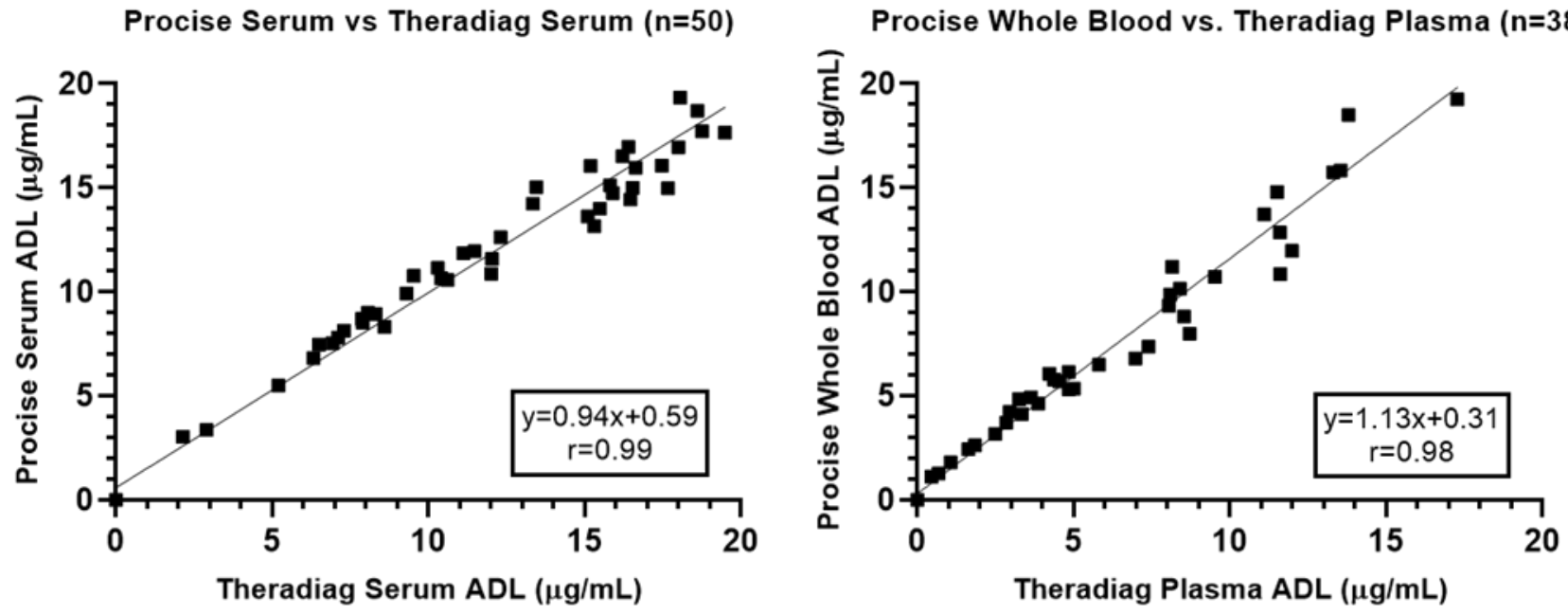


\section{TABLES}

Table 1. Results of IFX precision testing consisting of 2 lots, 1 operator, 2 runs per day, 2 reps per run across 20 days.

\begin{tabular}{|l|c|c|}
\hline \multicolumn{3}{|c|}{ Infliximab 20 Day Precision Summary } \\
\hline \multicolumn{1}{|c|}{ Level } & Avg [IFX] $(\mathrm{\mu g} / \mathrm{mL})$ & \%CV \\
\hline Low QC & 3.1 & $4.8 \%$ \\
\hline High QC & 20.3 & $2.8 \%$ \\
\hline Low Serum & 4.4 & $3.1 \%$ \\
\hline Med Serum & 9.0 & $3.3 \%$ \\
\hline High Serum & 36.5 & $2.8 \%$ \\
\hline
\end{tabular}

Table 2. Results of ADL precision testing consisting of 2 lots, 1 operator, 2 runs per day, 2 reps per run across 20 days.

\begin{tabular}{|l|c|c|}
\hline \multicolumn{3}{|c|}{10 Day Precision Summary } \\
\hline \multicolumn{1}{|c|}{ Level } & Avg [ADL] $(\mu \mathrm{g} / \mathrm{mL})$ & $\% C V$ \\
\hline Low QC & 2.8 & $3.5 \%$ \\
\hline High QC & 20.4 & $3.7 \%$ \\
\hline Low Serum & 4.7 & $2.7 \%$ \\
\hline Med Serum & 9.1 & $3.5 \%$ \\
\hline High Serum & 38.9 & $3.9 \%$ \\
\hline
\end{tabular}

Table 3. The analytical specificity of the Procise IFX and Procise ADL assays as measured by interference in assay quantitation of various potentially cross-reacting or interfering substances.

\begin{tabular}{|l|c|c|}
\hline \multirow{2}{*}{\multicolumn{1}{|c|}{ Interferents }} & \multicolumn{2}{c|}{$\begin{array}{c}\text { Maximum Concentration Tested at Which No Significant* Interference was } \\
\text { Observed }\end{array}$} \\
\cline { 2 - 3 } & Procise IFX Assay & Procise ADL Assay \\
\hline Methotrexate & $1 \mathrm{mM}$ & $2 \mathrm{mM}$ \\
\hline Azathioprine & $10 \mu \mathrm{M}$ & $10 \mu \mathrm{M}$ \\
\hline Bilirubin Conjugated & $0.3 \mathrm{mg} / \mathrm{dL}$ & $0.3 \mathrm{mg} / \mathrm{dL}$ \\
\hline Bilirubin Unconjugated & $1.2 \mathrm{mg} / \mathrm{dL}$ & $1.2 \mathrm{mg} / \mathrm{dL}$ \\
\hline Hemoglobin & $50 \mathrm{mg} / \mathrm{dL}$ & $50 \mathrm{mg} / \mathrm{dL}$ \\
\hline Triglycerides & $3.7 \mathrm{mmol} / \mathrm{L}$ & $3.7 \mathrm{mmol} / \mathrm{L}$ \\
\hline Total Protein & $8 \mathrm{~g} / \mathrm{dL}$ & $3 \mathrm{~g} / \mathrm{dL}$ \\
\hline Acetaminophen & $3 \mathrm{mg} / \mathrm{dL}$ & $40 \mathrm{mg} / \mathrm{dL}$ \\
\hline Acetylsalicylic Acid & $40 \mathrm{mg} / \mathrm{dL}$ & $20 \mu \mathrm{mol} / \mathrm{L}$ \\
\hline Ascorbic Acid & $20 \mu \mathrm{mol} / \mathrm{L}$ & $1000 \mathrm{IU} / \mathrm{mL}$ \\
\hline Rheumatoid Factors & $1000 \mathrm{IU} / \mathrm{mL}$ & $128 \mathrm{IU} / \mathrm{mL}$ \\
\hline Human Anti-Mouse Antibody & $128 \mathrm{IU} / \mathrm{mL}$ & $\mathrm{N} / \mathrm{A}$ \\
\hline Adalimumab & $20 \mu \mathrm{mL}$ & $20 \mu \mathrm{mg} / \mathrm{mL}$ \\
\hline Infliximab & $\mathrm{N} / \mathrm{A}$ & \\
\hline
\end{tabular}

*Significant interference was defined as $\pm 10 \%$ of the expected value 